\title{
A cross-national study of fear appeal messages in YouTube trending videos about COVID-19
}

\author{
Accepted to American Behavioral Scientist (2022)
}

\begin{abstract}
The ongoing COVID-19 outbreak has underlined the need for investigating the prevalence and nature of COVID-19 communication on social media. Applying the Extended Parallel Process Model, this study analyzed the use of fear appeals in 2,152 YouTube trending videos across six countries from January to May 2020. Findings revealed that COVID-19-themed videos gained early attention in Taiwan but encountered a prolonged delay in the US and Brazil. Specifically, COVID-19 videos featured the least in Brazil's trending list, with most of those spotlighted videos being from the Entertainment category. Results from automated content analysis further suggested that videos' threat levels exceeded efficacy beliefs. The imbalance of threat-efficacy messages was most significant in some of the hard-hit countries, such as Brazil and Russia, during the early stage of the pandemic.
\end{abstract}

Keywords: Fear appeals, efficacy, message design, YouTube trending videos, automated content analysis

\section{Author:}

Yee Man Margaret Ng, Ph.D., Assistant Professor

Department of Journalism \& Institute of Communications Research

University of Illinois Urbana-Champaign

Direct comments to ymn@illinois.edu 


\section{A cross-national study of fear appeal messages in YouTube trending videos about COVID-19}

As the COVID-19 pandemic continues, people across the world are preoccupied with concerns about this contagious illness. But while the pandemic itself wreaks havoc on our daily life, another threat—an "infodemic" (World Health Organization, 2020) —is going viral on social media and has further fueled public paranoia (Merino, 2014). The overabundance of (mis)information has made it exceedingly difficult for people to make informed decisions about how to keep their families safe. The uncertainty, amplified by confusing and contradictory messages from some government officials about the threat of the virus, has triggered an array of maladaptive behaviors, such as panic buying or proliferation of quack cures.

So, how does an infodemic create panic? One theoretical explanation lies in the Extended Parallel Process Model (EPPM) developed by communication scholar Kim Witte in 1992. Witte's model predicts how individuals react when confronted with fear-inducing stimuli: When individuals are unable to determine what information is and is not true, they cannot accurately evaluate the severity and susceptibility of a threat and less likely to take recommended actions (efficacy) to prevent disease transmission. Out of fear, people might even adopt defensive reactions when they feel helpless to act (Witte \& Allen, 2000). Therefore, to fight against the infodemic, journalists, public health officials, and other "gatekeepers" of information—such as social media platforms, not only need to find ways to counter misinformation but also to prioritize communication that combines threat and efficacy (Witte, 1992; Witte \& Allen, 2000).

COVID-19 is unlike previous global health crises, in part because of the collective access to communication technologies. YouTube, being one of the largest social media platforms 
(Statista, 2020), has been an important source of news (Stocking et al., 2020) and one of the "primary windows into the world" for young people (Perrin \& Anderson, 2019; Tufekci, 2018). However, YouTube faced the challenge of regulating virus-misinformation ${ }^{1}$ and elevating authoritative content. Considering that YouTube has emerged as an essential source of health information, it is important to understand to what extent the platform (intentionally or inadvertently) promotes and encourages public health messages, particularly messages that strengthen personal relevance and build self-efficacy regarding pandemic interventions.

Health communication strategies about COVID-19, largely affected by health policy and public discourses, could vary from country to country. However, little has been done in examining the incidence of fear appeals on social media across countries. Thus, this study focuses on six countries: Brazil, Russia, and the US. During the time of writing, these countries endured a significant rise in coronavirus cases. The study also focuses on New Zealand, Canada, and Taiwan, countries that were able to contain the virus and flatten the curve during the early stage of the pandemic. Applying the EPPM, this study (1) examines the characteristics of COVID-related trending videos on YouTube and (2) compares the extent and nature of threat and efficacy portrayals in COVID-related videos on YouTube across six countries.

This study extends the scale and scope of an existing health communication model by investigating the prevalence and nature of threat and efficacy messages on a cross-national dataset of YouTube videos collected during the COVID-19 pandemic. From a practical perspective, this study provides insight into the nature of health messages embedded in YouTube videos in various countries. In so doing, this study provides evidence suggesting the ways in

\footnotetext{
${ }^{1}$ A joint industry statement on COVID-19 from Microsoft, Facebook, Google, LinkedIn, Reddit, Twitter and YouTube: https://twitter.com/Microsoft/status/1239703041109942272/photo/1
} 
which the public would benefit from holding YouTube accountable to regulatory standards and YouTube adopting policies of further transparency.

\section{Literature Review}

\section{COVID-19 and Fear Appeals}

Designing and disseminating health communication messages (e.g., public service announcements or social media posts) during an unprecedented pandemic can be challenging, not to mention competing for attention with the constant stream of (mis)information. The construct of public health messages becomes extra pivotal in getting the messages across. In the domain of science communication, fear appeals, also called scare tactics, are a commonly used messaging approach to motivate behavior change. The Extended Parallel Process Model illustrates that a persuasive message using fear appeals needs to strike a balance between two concepts: threat and efficacy (Witte, 1992; Witte \& Allen, 2000). The construct of threat focuses on severity of and susceptibility to a risk. Severity is the seriousness of the threat (e.g., "More than 100,000 Americans have died from COVID-19.") and susceptibility refers to the likelihood that the threat is going to impact them or their beloved one (e.g., "The elderly are at increased risk for COVID-19.”). However, how people respond to the threat depends on the rational aspect of a message, which includes the construct of self efficacy and response efficacy. Self efficacy refers to the recommended measures that can address the pandemic (e.g., social distancing and handwashing); and response efficacy is information that helps increase individuals' confidence (skills, social support, and supplies) to perform the recommended behaviors to reduce explicit risk or eliminate it (e.g., "Wearing a mask is effective in preventing the spread of COVID-19."). 
An effective health-risk message is created with a balance between threat and efficacy. While individuals show better memory of messages with fear than messages with no emotional content (Snipes et al., 1999), appeals elicit a high level of fear but a low level of efficacy may cause people to reject the messages or even engage in fear-control strategies, such as counterarguing or discounting the messengers (Kok et al., 2018; Witte, 1992; Witte \& Allen, 2000). For example, O'Neill and Nicholson-Cole (2009) found that climate change messages using dramatic, shocking, or scary images to capture attention increase feelings of helplessness due to a lack of efficacy. In a similar vein, Droulers et al. (2017) and Gallopel-Morvan et al. (2011) found that tobacco fear appeals alone provoke avoidance reactions. Conversely, people are more likely to take preventive actions — danger-control strategies—against a threat when they perceive efficacy to act is higher than the fear or when both efficacy and threat are high (Witte \& Allen, 2000). For instance, Chen and Yang (2018) found that messages about preventing breast cancer contain high levels of threat and efficacy help raise women's intentions to adopt recommended practices, such as breast self-examination.

In the context of COVID-19, the word "pandemic" could be a frightening concept that makes people feel powerless, so increasing their agency is another critical strategy. To enhance individuals' perceived self efficacy to combat the illness, Abbott et al. (2020) suggested healthrisk messages offer encouragement and include "how-to" information, such as teaching people how to practice social distancing in different social settings. To gain response efficacy, healthrisk messages should cite positive, successful cases to convince people to agree that social distancing will work to slow the spread of COVID-19. In sum, fear appeals with feasible treatments and solutions to the problem can enhance communications and encourage compliance behaviors. Social media platforms could play a role in creating this equilibrium. 


\section{Roles of YouTube during COVID-19}

Since the world was gripped by the onset of the pandemic and nearly all public gatherings were called off in many countries, Internet users have turned to social media to adapt, cope, and find community. During the pandemic, YouTube experienced a tremendous surge in viewer traffic_-with overall viewing time in April 2020 doubled that of the same weeks in 2019 (Stelter, 2020). Being the second-most popular website worldwide (behind only Google; YouTube is one of Google's subsidiaries; Alexa, 2020), YouTube also has become an important source of news for many Americans (Stocking et al., 2020). However, YouTube's affordance is a double-edged sword during outbreak responses: Its audiovisual modality draws more attention and improves recall as compared to text alone, making the platform an effective tool for communicating health-risk information (Basch et al., 2017; Fung et al., 2016); Yet, its low barriers for media production and dissemination enable the rapid diffusion of misleading or inaccurate information during the pandemic (D'Souza et al., 2020; Li et al., 2020), forcing the platform to remove thousands of videos and take steps to advocate information from global and local health organizations (Benson, 2020).

Much YouTube research has focused on videos with high viewing counts (D’Souza et al., 2020; Li et al., 2020). However, YouTube maintains a regularly updated list of trending videos (https://www.youtube.com/feed/trending) that aims to "capture the breadth of what's happening on YouTube and in the world." (YouTube, 2020). Amongst the many new videos on YouTube on any given day, trending videos are not necessarily the most-viewed videos overall. Instead, YouTube (2020) considers a combination of signals, such as users' engagement (number of views, comments, and likes) and how quickly the video is generating views, to determine which 
videos to spotlight. Yet, the exact breakdown of the metric has never been disclosed, which leads to suspicion of manipulation and quality controls behind the door that favors traditional media outlets (Alexander, 2019). Hence, in the case that YouTube does actively influence video order, the trending list of videos, arguably, not only showcases a facet of public agenda but also symbolizes YouTube's internal agenda.

Since the platform is designed to host user-generated videos and collect revenue from advertisements, any social responsibilities that have arisen from the service's popularity and the content provided by its user base might seem to be a secondary consideration. The trending list is a better alternative to study message constructs, other than videos with high viewing counts, as the list also reflects YouTube's efforts to promote or encourage public health messages. This leads to the first research question:

\section{RQ1: To what extent do COVID-related videos appear on YouTube trending list?}

\section{Extending the Scale and Scope of Fear Appeals Research}

Prior research has content analyzed the use of threat and efficacy constructs in YouTube videos. For example, Paek et al. (2010) found that threat appeals are the predominant message strategy (other than humor and social appeals) for YouTube antismoking campaign videos. Likewise, Krajewski et al. (2019) found that threat messages often outweigh efficacy messages regarding global water crisis public service announcements. However, the samples used in these studies were relatively small and not generalizable. For instance, Paek et al. (2010) studied 934 antismoking video clips in English and Krajewski et al.'s (2019) analysis was restricted to around a hundred videos that were short ( $<$ two minutes) and appeared as the first 200 in the 
search. To a further extent, YouTube's influence is not restricted to the US but many other countries. YouTube's most popular channels post a substantial amount of content in languages other than English (Van et al., 2019). The inclusion of only English YouTube videos in previous COVID studies (D’Souza et al., 2020; Li et al., 2020) presents a language bias and further limits research generalizability, mitigating our ability to understand COVID-19 as a global phenomenon.

Amid the pandemic, some of the world's largest economies - the US, Brazil, and Russia - have faced relentless criticism of slow and ineffective containment of the outbreak. Since the start of the pandemic, political figures, like President Trump and President Bolsonaro in Brazil, publicly downplayed the coronavirus risk (Bump, 2020; Linvill \& Warren, 2020). The conflicting statements between officials and scientists could have made the public more susceptible to rumors and misinformation about the pandemic's scale, origin, prevention, and treatment. Conversely, The New York Times' columnist has lauded Taiwan, Canada, and New Zealand for their success in flattening the infection rates curve (Goldberg, 2020). Early in the pandemic, the Taiwanese government provided regular public service announcements about cooperative strategy and built digital platforms, such as chatbot and vTaiwan, to improve public health information (Lin et al., 2020). Leaderships in Canada and New Zealand have taken a clear stance on the severity of the virus. While borders are still shut, but inside the countries, normal life returned. These countries were testaments to what early action and aggressive monitoring brings to the table when battling a pandemic. Since official responses differed greatly across these countries, national public discourses and health messaging strategies on YouTube might also show significant variation. 
Although YouTube is an important tool for health communication during outbreak responses (Moorhead et al. 2013), researchers' attention on the platform has been disproportionate to its influence among the general population. One reason is examining the message content of YouTube videos can be daunting. Yet, YouTube offers an open Application Programming Interface (API), which to some extent is more generous than Twitter'sresearchers can query search results from YouTube and scrape the entire history of a given channel. This study attempts to answer Rains' (2020) call to apply big data and computational techniques to extend the literature of fear appeals. Since web use is blossoming along traditional lines, defined by languages and geographies (Ng \& Taneja, 2019), beyond English-speaking countries (the US, Canada, and New Zealand), this study examines YouTube's message constructs in Taiwan (Traditional Chinese), Brazil (Portuguese), and Russia (Russian) through video transcripts. Employing supervised machine learning methods, this study analyzes phrases and topics related to fear appeals in broader scopes and scales.

On the basis of the above research, this study examines how the constructs of threat and efficacy present in YouTube videos across countries. This study proposes other three research questions:

RQ2: What are the descriptive characteristics of COVID-related videos, and how do those characteristics differ across countries?

RQ3: To what extent are threat messages and efficacy messages present in COVIDrelated videos, and how do those portrayals differ across countries? 


\section{RQ4: How balanced are the presence of threat messages and efficacy messages in COVID-related videos on YouTube trending lists across countries?}

\section{Method}

\section{Data collection}

While YouTube does not provide country level statistics at the video level or individual user level, it maintains a regularly updated list of "trending videos" for each target country. Querying YouTube's API (mostpopular/regioncode), I collected the first 200 trending videos of the US, Russia, Brazil, Canada, Taiwan, and New Zealand from January 1, 2020 to May 31, 2020 (five months), four times a day. Videos that trended for two or more times a day or days had their details entered in the data set multiple times. This yielded 29,904 unique videos.

To select COVID-related videos, I first extracted videos that contained the word "COVID" in video tags, descriptions, or titles. I then examined the top-10-frequent words that accompanied the starting word "COVID" in each country, soliciting logical variants, slang terms, and misspellings. All non-English tags (vocabulary) were translated into English using Google Translate API (via python library googletrans) and were manually verified by native speakers who ensured that these words were related to the pandemic. Previous research has showed that Google Translate and the translations of human translators ("gold standard") are comparable (de Vries et al., 2018). Through this process, Taiwanese were more likely to use term “武漢肺炎”

(Wuhan virus) and Russian used коронавирус to refer to the pandemic. Using all these relevant key words, I redid a search and the final dataset yielded 2,788 unique COVID-related videos.

Video metadata and transcripts. Video metadata includes video ID, title, tags, channel name, trending date, uploaded date, assigned category, as well as popularity metrics (i.e., the 
number of views, likes, dislikes, and comments). Transcripts of those 2,788 videos were also collected. YouTube transcripts are either uploaded by creators or automatically generated (at the creators' request) by Google's speech recognition technology that has reported a 95\% word accuracy rate for English (Protalinski, 2017). This study successfully collected transcripts from 2,152 videos $(77.2 \%)$. That represented more than $80 \%$ of videos for most of the countries, except for Taiwan, which only $65.3 \%$ of its videos enabled the subtitle feature. YouTube transcripts are available as a stream of text, with no punctuations or speaker segmentations.

\section{Analytical Procedures}

To answer RQ1 and RQ2, this study examines the following characteristics of COVIDrelated videos:

Proportion. To determine if YouTube prioritized COVID information, I calculated the percentage of COVID-related trending videos over the total number of trending videos of each country.

Date of the first video. To estimate how early COVID information gained public attention, I tracked the date when the first video COVID-related video appeared in the YouTube's trending list of each country.

Video category. I further analyzed category (genre) assignments of each trending video. YouTube allows creators to sort their channels and videos into one of the 32 categories, such as Music, Sports, News \& Politics, Education, and Science \& Technology. Although channels and videos can be labelled independently of each other, for example, the creator of an Entertainment channel might upload a video and label the video as Comedy, three-fourths of the channels have 
the same category assigned to $80 \%$ of their videos (Bärtl, 2018). I examined which categories were predominantly represented for each country.

\section{Human Labelling and Automated Content Analysis}

Previous studies (Emery et al., 2014; Krajewski et al., 2019) considered a message containing a threat or a efficacy construct even when the reelevated themes/words just appeared once. A binary 0-1 (no-yes) coding system may work well for short communication, such as tweets or news headlines, to indicate a construct presence. However, YouTube videos are usually a much longer form of communication. To answer RQ3 and RRQ4, I split each transcript into segments of 40 words ( $\sim 200$ charterers, a similar length of a tweet) $(N=230,438$ segments) to calculate four construct density scores (i.e., severity, susceptibility, self efficacy, and response efficacy). Each density score was estimated based on a summation of the number of a construct appearance, divided by the number of segments of a transcript.

To address the issue of language specificity, four coders, who were proficient in English and were native speakers of one of the following languages - Traditional Chinese, Portuguese, or Russian - took part in the content analysis. I further employed Google Translate to convert nonEnglish transcripts to English as a crosscheck for coding. A 0-1 (no-yes) coding system was used to identify the presence or absence of one of the constructs: severity, susceptibility, self efficacy, or response efficacy, respectively. Therefore, a segment could have multiple constructs. Consistent with Witte (1992), the EPPM constructs were operationalized as below:

Severity. Severity was defined as the magnitude or seriousness of COVID-19. Videos were coded to indicate whether they referenced (1) magnitude of COVID (e.g., 
widespread/pandemic/mortality rate), (2) seriousness of illness (e.g., death/hospitalization/symptoms/implications), or (3) concerns about mutation or resistance.

Susceptibility. Susceptibility was defined as any references to individuals or groups at higher risk for severe COVID-19. Videos were coded to indicate whether they referenced (1) risk for severe illness increases with age; (2) older adults at increased risk with those aged 85 or older are at the greatest risk; (3) those of any age with certain underlying medical conditions are at increased risk; or (4) other risk factors (pregnancy and other sociodemographic factors, etc.)

Self-efficacy. Self-efficacy was operationalized whether the video mentioned any (1) individual-level (e.g., covering cough, vaccinations) or societal-level behaviors (e.g., closings, quarantines) recommended by the CDC (see also Bandura, 1998); (2) "how to" information for protection measures, (3) words of encouragement, or (4) instructions/links to other health resources (e.g., websites, phone number) for updates.

Response efficacy. Response efficacy was assessed whether (1) the videos discussed recommended actions were effective or not, (2) mentioned the number of those who recovered from the virus, or (3) about individuals who had triumphed over the virus and their stories.

Table 1 presents the codebook and sample messages.

[INSERT TABLE 1 HERE]

Coders received training that consisted of watching COVID-related YouTube videos, and meeting as a group to review, discuss, and refine coding criteria. Questions about and discrepancies with the coding criteria were resolved by consensus. To calculate the intercoder reliability, each coder hand-labeled a random sample of 1,000 (original or translated) English segments and another 1,000 segments of their language. Intercoder reliability was found to be acceptably high between coders (Kappa $=.82$ for Chinese transcripts; .86 for Portuguese; .84 for 
Russian; Landis \& Koch, 1977), reassuring a decent performance of YouTube auto-translation (De Vries et al., 2018; Windsor et al., 2019). After reaching a satisfactory level of reliability, the coders all together analyzed a random sample of 12,000 segments $(5.21 \%$ of the total). These human-coded segments were then used as input for a supervised machine learning procedure to predict whether remaining segments contained the constructs.

During the supervised machine learning procedure, the 12,000 human-coded segments were randomly split into training (three-fourths of data) and testing sets (one-fourth). Both sets were stratified and included the same ratio of threat and efficacy. Segments were preprocessed as a list of weighted words ("bag-of-words" approach). Rare words were assigned a greater weight and assumed to carry a higher discriminatory power. Gradient Boosting Classifier ${ }^{2,3}$ (Schapire \& Freund, 2013) was used to classify each transcript segment and subsequently automatically classify the larger dataset of transcripts for EPPM constructs. After the classification, segments were reassembled into original transcripts and returned the density scores.

To answer RQ4, this study followed Witte's additive approach (1996) and curated a threat-efficacy index to represent the balance between threat and efficacy message in each video. Severity items were summed with susceptibility items, and then subtracted from the summation of self- and response efficacy (no interaction between the two is proposed).

\footnotetext{
2 Three popular classifiers: Random Forest (Breiman, 2001), Logistic Regression (Cox, 1958), and Gradient Boosting Classifier (Schapire \& Freund, 2012) were used to classify each transcript segment. To evaluate model performance, a 10-fold cross-validation was conducted to assess how well the training model generalized to the testing data set. Cross-validation helps avoid overfitting. Gradient Boosting Classifier achieved the best precision (.85), recall (.83), F1-score (.85), and accuracy (.87).

${ }^{3}$ Gradient boosting machines are a family of powerful machine learning techniques that have shown considerable success in a wide range of practical applications. In gradient boosting, the model consecutively minimizes the loss of the model by adding weak learners using a gradient descent-like procedure.
} 
Considering the heterogeneity of the variances, I performed Welch ANOVAs on four density scores. When results were significant, I used Games Howell post-hoc tests (Games, Keselman, \& Rogan, 1981), an improved version of Tukey's post-hoc tests for unequal group sizes and unequal variances, to assess pairwise differences.

\section{Results}

To answer RQ1, to what extent do COVID-related videos appear on YouTube trending lists. Results showed that, during the five-month period, New Zealand had the most COVIDrelated video on its trending list (7.1\%), followed by Russia (6.1\%). Conversely, Brazil had the lowest portion of COVID-related videos (2.4\%) on its trending list.

RQ2 asked: what are the descriptive characteristics of COVID-related videos, and how do those characteristics differ across countries? The results showed that COVID-related videos first appeared in Taiwan's trending list on January 1, 2020. However, it took another three weeks, until January 22, for videos to be spotlighted on Russia's and New Zealand's lists. Brazil was the last country to have COVID-related videos on its trending list (January 28). Regarding video categories, "News \& Politics" was the dominant category for all countries, except for Brazil. While the portion of the "News \& Politics" videos was close to $80 \%$ in Taiwan, Brazil just had only one-fifth of the COVID-related videos from "News and Politics." Other common categories included "Education," "People \& Blogs," and "Comedy." Table 2 presents the details.

\section{[INSERT TABLE 2 HERE]}

RQ3 asked: to what extent are threat and efficacy messages present in COVID-related videos, and how do those portrayals differ across countries. Welch ANOVAs revealed significant differences for all construct density across countries: severity $(F=51.01, p<.001)$, 
susceptibility $(F=13.23, p<.001)$, self efficacy $(F=8.89, p<.001)$, and response-efficacy constructs $(F=16.18, p<.001)$.

Results showed that Russia's severity density $(M=.047)$ was significantly higher than that of the US $(M=.039)$, Canada $(M=.035)$, Taiwan $(M=.035)$, and New Zealand $(M=.033)$. In turn, Brazil $(M=0.044)$ and the US were significantly higher than that of New Zealand. In the same vein, Russia's videos had the highest susceptibility density $(M=.010)$, followed closely by Brazil $(M=.010)$. Russia's susceptibility density was significantly higher than that of the US ( $M$ $=.008)$, Taiwan $(M=.008)$, and New Zealand $(M=.007)$. Susceptibility density scores of Brazil and Canada $(M=.009)$ were higher than that of New Zealand. For self efficacy, New Zealand's density score $(M=.016)$ was significantly lower than that of Canada $(\mathrm{M}=.023)$, the US (M $=.021)$, and Russia $(M=.020)$. For response efficacy, the US's was significantly higher than that of Brazil's $(M=.005)$, New Zealand's $(M=.004)$, and Russia's $(M=.003)$. Canada $(M=.004)$ was significantly higher than that of Brazil and Russia. Figure 1 is a visualization to compare density scores across countries.

\section{[INSERT FIGURE 1 HERE]}

RQ4 asked how balanced threat messages and efficacy messages in COVID-related videos on YouTube trending lists across countries are. Consider all countries, efficacy density scores (summation of self efficacy and response efficacy) $(M=.022, S D=.011)$ was significantly lower than threat density scores (summation of severity and susceptibility) ( $M$ $=.050, S D=.020), t(2,189)=61.644, p<.002$. There was also a significant discrepancy among countries regarding their differences between threat and efficacy $(F=43.15, p<.001)$, with Russia $(M=.034)$ and Brazil $(M=.032)$ showed a significantly higher threat-efficacy imbalance than the rest of the countries studied. 
Table 3 presents the Games-Howell Post-Hoc analysis.

[INSERT TABLE 3 HERE]

\section{Discussion}

Drawing upon the Extended Parallel Process Model (Witte, 1992; Witte \& Allen, 2000), this study examined the characteristics of COVID-related videos on YouTube and assessed the extent threat and efficacy messages are present in COVID-related videos across six countries. Using automated content analysis, I analyzed the transcripts of 2,152 YouTube trending videos. The results reveal that YouTube neither proactively promotes COVID-19 videos over other topics nor prioritizes communication that combines threat and efficacy messages. This claim is particularly obvious when examining trending videos of some of the worst-hit countries by coronavirus.

\section{General Video Characteristics}

Much of the world remained in an information vacuum even as first signs of COVID-19 emerged from Wuhan, China in late 2019. Yet, Taiwan was the exception. As a close neighbor of mainland China, Taiwan was expected to have one of the highest virus caseloads. However, I found that Taiwan had the first COVID-related videos hit its YouTube Trending tab on January 1 - a much earlier time before the country recorded its first coronavirus case on January 21. Early public attention to the virus contributes to Taiwan's success in the battle against the COVID-19 as there was more time for citizens to anticipate disease prevention measures and digest related health information. On the contrary, that information vacuum seems to last much longer in the US and Brazil than in other parts of the world. The first COVID-related video only 
appeared on the US's trending list on January 26 and Brazil's on January 28. Although the US confirmed its first COVID-19 case on January 20, YouTube did not capture the instance in its trending list. The delay shows a lack of public interest in COVID-19 in the US during the early containment and mitigation periods; results are consistent with another analysis that is based on Google Trends data (Husain et al., 2020).

Since the outbreak, COVID-related videos have appeared on countries' trending lists in various proportions, ranging from $2.4 \%$ in Brazil to $7.1 \%$ in New Zealand. The proportions were relatively small, considered the crisis hit hard in some of the countries studied. The small proportions could imply that COVID-related information was primarily missing from public agenda or YouTube did not take an active role to prioritize COVID-related information over other topics. To tell a complete story, I further investigated the categories (genres) those trending videos belonged to, which to some degree, hints at the purposes and narratives of the videos. Among countries investigated, Brazil had the least proportion of COVID-related videos (20.9\%) from "News \& Politics," but with more of its trending videos being from the "Entertainment" category $(22.9 \%)$. Without any close examination of the video content, it is unfair to say videos labeled as "News \& Politics" convey better health information than "Entertainment" videos. However, the category proportion is one way to reflect what information sources - whether they are more fact-based or opinionated - people relied on to understand the pandemic. Particularly, research shows that people who watch more soft news are relatively more cynical about politics than people who watch more hard news (Boukes \& Boomgaarden, 2015). The distrust may vary people's perceptions and motives to follow recommended actions.

\section{Threat Levels Exceed Efficacy Beliefs}


Consistent with previous research (Krajewski et al., 2019; Paek et al., 2010), this study found that threat messages are more prevalent than efficacy messages on YouTube videos, running the risk of feeding fear to the public agenda. Although people are able to recall messages with fear appeals better (Snipes et al., 1999), videos that employ the language of threat without providing reasoning may foster the very individualism and competitiveness that could turn sensible behaviors into maladaptive reactions, such as panic buying (Olson, 1995; Witte, 1992). Yet, there are several plausible reasons to explain the imbalance. First, during the early stage of an outbreak, what is known is usually fear-inducing (e.g., deadly diseases, serious complications); what is unknown, such as why certain people show no symptoms or whether vaccination is an effective cure, leaves little sense of efficacy. At the early stage, video creators could only explain what could be done to minimize risks to increase the efficacy of a video.

However, although YouTube content shows a low efficacy score, it is important to note that YouTube includes other design features to raise self-efficacy. For example, YouTube provides other visual cues, such as embedding the hyperlink of the CDC website below the video window, to direct people to the latest information about COVID-19. These design features also help increase individuals' confidence to take action.

\section{Threat-efficacy Imbalance in "Hard-hit" Countries}

"Hard-hit" nations, namely Brazil and Russia, showed a significantly higher threatefficacy imbalance than the rest of the countries studied. The larger imbalance might attribute to government leaderships' slow and muddled responses to containing the spread of the virus. 
These countries have seen a disturbing surge of infections (increased fear) and a lack of coherent and effective responses (low collective efficacy). Therefore, public agenda follows and less likely to include what are considered as recommended actions in news and videos. In the US, although Trump's administration showed a lack of national coordination, its own top disease expert, Dr. Anthony Fauci, has grown increasingly vocal in his concerns about the national surge in coronavirus cases and made constant media appearances to correct any false statements made by Trump. The CDC has also advised Americans since April to use face coverings in public, calling masks as "one of the most powerful weapons we have to slow and stop the spread of the virus." Therefore, people in the US were able to expose to health information from various authorities and may be able to correct any misperceptions about the COVID-19 and be more certain of what health actions should be taken.

\section{Limitations}

There are several reasons for caution when interpreting data from this study. First, the measurement of threat and efficacy has been a long-discussed issue and does not have a definitive answer (e.g., Weinstein, 2000). This study followed Witte's (1996) additive model to estimate the index of threat-efficacy balance. However, Witte also cautioned that threat perceptions need to reach a certain threshold before people become motivated to consider a health-protective action. Yet, this threshold has never been specified. Furthermore, the likelihood and valence of disease severity items are quite different (Fishbein et al., 2001). For example, the risk of death or job loss brings different threat arousal to different individuals. However, in this study, I treated all severity items same weight when I quantified the threat scores. Future studies should pay close attention to assessing the measurement issues. 
Second, for analytical purposes, this study reduced videos to forms of text and metadata, which might lead to a loss in valuable communicative features. YouTube is multimodal—its visual imagery, soundtracks (tones and sounds), and transcripts, can be distinctly analyzed. For videos about COVID-19, fear appeal messages could use tactics such as showing explicit pictures of individuals who have died from the virus; User comments and advertisements that appear on the same page as the video may be analyzed as well. Yet, the current computational approach offers a board overview of a large video corpus before drilling down for a targeted, multimodal examination.

\section{Conclusion}

Slowing COVID-19 viral transmission requires significant shifts in behavior. It is known that fear appeals have an impact on health compliance. However, an effective fear-inducing message needs to strike a balance between threat and efficacy (Witte \& Allen, 2000). The results of this study showed that COVID-related videos' threat levels exceeded their levels of efficacy for all six countries studied. The imbalance of threat-efficacy messages was most significant in some of the hard-hit countries, such as Brazil and Russia, during the early stage of the pandemic. These findings alert content creators and social media platforms to create a threat-efficacy equilibrium, prioritizing content that promotes a sense of self-efficacy and community efficacy and bolstering viewers' belief that effective protective actions are within their reach. The world needs to discover calm amidst the coronavirus chaos. 


\section{References}

Abbott, A., Askelson, N., Scherer, A. M., \& Afifi, R. A. (2020). Critical reflections on COVID-19 communication efforts targeting adolescents and young adults. Journal of Adolescent Health, 67(2), 159-160. https://doi.org/10.1016/j.jadohealth.2020.05.013

Alexa. (2020). The top 500 sites on the web. Alexa. https://www.alexa.com/topsites/

Alexander, J. (2019). YouTube's Trending section puts creators at a huge disadvantage over big brands. The Verge. https://www.theverge.com/2019/5/29/18642833/youtube-trending-coffee-break-pewdiepie-late-night-sports-highlights

Bandura, A. (1998). Personal and collective efficacy in human adaptation and change. In Advances in psychological science, Vol. 1. Social, personal, and cultural aspects (Vol. 1, pp. 51-71). Psychology Press/Erlbaum (UK) Taylor \& Francis.

Bärtl, M. (2018). YouTube channels, uploads and views: A statistical analysis of the past 10 years. Convergence, 24(1), 16-32. https://doi.org/10.1177/1354856517736979

Basch, C. H., Fung, I. C. H., Hammond, R. N., Blankenship, E. B., Tse, Z. T. H., Fu, K. W., Ip, P., \& Basch, C. E. (2017). Zika virus on youtube: An analysis of english-language video content by source. Journal of Preventive Medicine and Public Health, 50(2), 133-140. https://doi.org/10.3961/jpmph.16.107

Benson, T. (2020). Facebook announces how it plans to help fight the coronavirus. Inverse. https://www.inverse.com/innovation/facebook-is-giving-the-world-health-organization-free-ads-to-combat-the-coronavirus

Boukes, M., \& Boomgaarden, H. G. (2015). Soft news with hard consequences? Introducing a nuanced measure of soft versus hard news exposure andi its relationship with political cynicism. Communication Research, 42(5), 701-731. 
https://doi.org/10.1177/0093650214537520

Breiman, L. (2001). Random forests. Machine learning, 45, 5-32. https://doi.org/10.1023/A:1010933404324

Bump, P. (2020). Trump again downplays coronavirus by comparing it to the seasonal flu. It's not a fair comparison. - The Washington Post. The Washington Post. https://www.washingtonpost.com/politics/2020/03/24/trump-again-downplayscoronavirus-by-comparing-it-seasonal-flu-its-not-fair-comparison/

Chen, L., \& Yang, X. (2019). Using EPPM to evaluate the effectiveness of fear appeal messages across different media outlets to increase the intention of breast self-examination among Chinese women. Health Communication, 34(11), $1369-1376$. https://doi.org/10.1080/10410236.2018.1493416

Cox, D. R. (1958). The regression analysis of binary sequences. Journal of the Royal Statistical Society. Series B (Methodological), $20,215-242$.

D’Souza, R. S., D’Souza, S., Strand, N., Anderson, A., Vogt, M. N. P., \& Olatoye, O. (2020). YouTube as a source of medical information on the novel coronavirus 2019 disease (COVID-19) pandemic. Global Public Health, 15(7), 935-942. https://doi.org/10.1080/17441692.2020.1761426

De Vries, E., Schoonvelde, M., \& Schumacher, G. (2018). No longer lost in translation: Evidence that Google translate works for comparative bag-of-words text applications. Political Analysis, 26(4), 417-430. https://doi.org/10.1017/pan.2018.26

Droulers, O., Gallopel-Morvan, K., Lacoste-Badie, S., \& Lajante, M. (2017). The influence of threatening visual warnings on tobacco packaging: Measuring the impact of threat level, image size, and type of pack through psychophysiological and self-report 
methods. PLoS ONE, 12(9), e0184415. https://doi.org/10.1371/journal.pone.0184415

Emery, S. L., Szczypka, G., Abril, E. P., Kim, Y., \& Vera, L. (2014). Are you scared yet? Evaluating fear appeal messages in tweets about the Tips Campaign. Journal of Communication, 64(2), 278-295. https://doi.org/10.1111/jcom.12083

Fishbein, M., Triandis, H. C., Kanfer, F. H., Becker, M., Middlestadt, S. E., \& Eichler, A. (2001). Factors influencing behavior and behavior change. In A. Baum, T. A. Revenson, \& J. E. Singer (Eds.), Handbook of Health Psychology (pp. 3-16). Lawrence Erlbaum Associates Publishers.

Fung, I. C. H., Duke, C. H., Finch, K. C., Snook, K. R., Tseng, P. L., Hernandez, A. C., Gambhir, M., Fu, K. W., \& Tse, Z. T. H. (2016). Ebola virus disease and social media: A systematic review. In American Journal of Infection Control (Vol. 44, Issue 12, pp. 1660-1671). Mosby Inc. https://doi.org/10.1016/j.ajic.2016.05.011

Gallopel-Morvan, K., Gabriel, P., Le Gall-Ely, M., Rieunier, S., \& Urien, B. (2011). The use of visual warnings in social marketing: The case of tobacco. Journal of Business Research, 64(1), 7-11. https://doi.org/10.1016/j.jbusres.2009.09.012

Games, P. A., Keselman, H. J., \& Rogan, J. C. (1981). Simultaneous pairwise multiple comparison procedures for means when sample sizes are unequal. Psychological Bulletin, 90(3), 594-598. https://doi.org/10.1037/0033-2909.90.3.594

Goldberg, M. (2020). In some countries, normal life is back. Not here. The New York Times. https://www.nytimes.com/2020/07/13/opinion/us-coronavirus-trump.html

Husain, I., Briggs, B., Lefebvre, C., Cline, D. M., Stopyra, J. P., O’Brien, M. C., Vaithi, R., Gilmore, S., \& Countryman, C. (2020). Fluctuation of public interest in COVID-19 in the United States: Retrospective analysis of Google trends search data. JMIR 
Public Health and Surveillance, 6(3). https://doi.org/10.2196/19969

Kok, G., Peters, G. J. Y., Kessels, L. T. E., ten Hoor, G. A., \& Ruiter, R. A. C. (2018). Ignoring theory and misinterpreting evidence: The false belief in fear appeals. Health Psychology Review, 12(2), 111-125. https://doi.org/10.1080/17437199.2017.1415767

Krajewski, J. M. T., Schumacher, A. C., \& Dalrymple, K. E. (2019). Just turn on the faucet: A content analysis of PSAs about the global water crisis on YouTube. Environmental Communication, 13(2), 255-275. https://doi.org/10.1080/17524032.2017.1373137

Landis, J. R., \& Koch, G. G. (1977). An application of hierarchical Kappa-type statistics in the assessment of majority agreement among multiple observers. Biometrics, 33(2), 363. https://doi.org/10.2307/2529786

Li, H. O. Y., Bailey, A., Huynh, D., \& Chan, J. (2020). YouTube as a source of information on COVID-19: A pandemic of misinformation? BMJ Global Health, 5(5). https://doi.org/10.1136/bmjgh-2020-002604

Lin, C., Braund, W. E., Auerbach, J., Chou, J. H., Teng, J. H., Tu, P., \& Mullen, J. (2020). Policy decisions and use of information technology to fight COVID-19, Taiwan. In Emerging Infectious Diseases (Vol. 26, Issue 7, pp. 1506-1512). Centers for Disease Control and Prevention (CDC). https://doi.org/10.3201/eid2607.200574

Linvill, D. L., \& Warren, P. (2020). Yes, Russia spreads coronavirus lies. But they were made in America. The Washington Post. https:/www.washingtonpost.com/outlook/2020/04/02/yes-russia-spreads-coronavirus-lies-they-were-made-america/

Merino, J. G. (2014). Response to Ebola in the US: Misinformation, fear, and new opportunities. In BMJ (Online) (Vol. 349). BMJ Publishing Group. https://doi.org/10.1136/bmj.g6712 
Moorhead, S. A., Hazlett, D. E., Harrison, L., Carroll, J. K., Irwin, A., \& Hoving, C. (2013). A new dimension of health care: systematic review of the uses, benefits, and limitations of social media for health communication. Journal of Medical InternetRresearch, 15(4), https://doi.org/ 10.2196/jmir.1933

Nabi, R. L., Roskos-Ewoldsen, D., \& Dillman Carpentier, F. (2008). Subjective knowledge and fear appeal effectiveness: Implications for message design. Health Communication, 23(2), 191-201. https://doi.org/10.1080/10410230701808327

Ng, Y. M. M., \& Taneja, H. (2019). Mapping User-Centric Internet Geographies: How Similar are Countries in Their Web Use Patterns? Journal of Communication, 69(5), 467-489. https://doi.org/10.1093/joc/jqz030

O’Neill, S., \& Nicholson-Cole, S. (2009). "fear won't do it": Promoting positive engagement with climate change through visual and iconic representations. Science Communication, 30(3), 355-379. https://doi.org/10.1177/1075547008329201

Olson, E. L. (1995). How magazine articles portrayed advertising from 1900 to 1940. Journal of Advertising, $24(3), 41$. https://doi.org/10.1080/00913367.1995.10673482

Paek, H. J., Kim, K., \& Hove, T. (2010). Content analysis of antismoking videos on YouTube: Message sensation value, message appeals, and their relationships with viewer responses. Health Education Research, 25(6), 1085-1099.

https://doi.org/10.1093/her/cyq063

Perrin, A., \& Anderson, M. (2019). Social media usage in the U.S. in 2019. Pew Research Center. https://www.pewresearch.org/fact$\operatorname{tank} / 2019 / 04 / 10 /$ share-of-u-s-adults-using-social-media-including-facebook-is-mostly-unchanged-since-2018/

Protalinski, E. (2017). Google’s speech recognition technology now has a $4.9 \%$ word error rate. VentureBeat. 
https://venturebeat.com/2017/05/17/googles-speech-recognition-technology-now-has-a-4-9-word-error-rate/

Rains, S. A. (2020). Big data, computational social science, and health communication: A review and agenda for advancing theory.

Health Communication, 35(1), 26-34. https://doi.org/10.1080/10410236.2018.1536955

Schapire, R. E., \& Freund, Y. (2012). Boosting: Foundations and algorithms. Cambridge, MA: MIT Press.

Snipes, R. L., LaTour, M. S., \& Bliss, S. J. (1999). A model of the effects of self-efficacy on the perceived ethicality and performance of fear appeals in advertising. Journal of Business Ethics, 19(3), 273-285. https://doi.org/10.1023/A:1005822414588

Statista. (2020). Most popular social networks worldwide as of January 2021, ranked by number of active users (in millions). Social Media and User-Generated Content. https://www.statista.com/statistics/272014/global-social-networks-ranked-by-number-ofusers/

Stelter, Brian. (2020). YouTube CEO says people are discovering different kinds of vvideos as the pandemic rages. CNN. https://www.cnn.com/2020/04/23/media/youtube-videos-pandemic/index.html.

Stocking, G., Van Kessel, P., Barthel, M., Matsa, K. E., \& Khuzam, M. (2020). Many Americans get news on YouTube, where news organizations and independent producers thrive side by side. Pew Research Center.

https://www.journalism.org/2020/09/28/many-americans-get-news-on-youtube-where-news-organizations-and-independentproducers-thrive-side-by-side/

Tufekci, Z. (2018). YouTube, the Great Radicalizer. The New York Times.

https://www.nytimes.com/2018/03/10/opinion/sunday/youtube-politics-radical.html 
Van, K. P., Skye, T., \& Aaron, S. (2019). 1. Popular YouTube channels produced a vast amount of content, much of it in languages other than English. Pew Research Center. https://www.pewresearch.org/internet/2019/07/25/popular-youtube-channelsproduced-a-vast-amount-of-content-much-of-it-in-languages-other-than-english/

Weinstein, N. D. (2000). Perceived probability, perceived severity, and health-protective behavior. Health Psychology, 19(1), 65-74. https://doi.org/10.1037/0278-6133.19.1.65

Windsor, L. C., Cupit, J. G., \& Windsor, A. J. (2019). Automated content analysis across six languages. PLoS ONE, 14(11). https://doi.org/10.1371/journal.pone.0224425

Witte, K. (1992). Putting the fear back into fear appeals: The extended parallel process model. Communication Monographs, 59(4), 329-349. https://doi.org/10.1080/03637759209376276

Witte, K. (1996). Fear as motivator, fear as inhibitor. In Handbook of Communication and Emotion (pp. 423-450). Elsevier. https://doi.org/10.1016/b978-012057770-5/50018-7

Witte, K., \& Allen, M. (2000). A meta-analysis of fear appeals: Implications for effective public health campaigns. Health Education and Behavior, 27(5), 591-615. https://doi.org/10.1177/109019810002700506

World Health Organization. (2020). Novel Coronavirus(2019-nCoV) Situation Report-13. https://www.who.int/docs/defaultsource/coronaviruse/situation-reports/20200202-sitrep-13-ncov-v3.pdf

YouTube. (2020). Trending on YouTube. https://support.google.com/youtube/answer/7239739?hl=en 
Table 1

Theoretical constructs and sample messages from YouTube video transcripts.

\begin{tabular}{|c|c|c|}
\hline Constructs & Operational definitions & Examples \\
\hline Severity & $\begin{array}{l}\text { Videos referencing } \\
\text { - Magnitude of COVID } \\
\text { - Seriousness of illness } \\
\text { - Concerns about mutation or resistance }\end{array}$ & $\begin{array}{l}\text { "...if we do nothing calls it will be a catastrophe } 30 \\
5060 \text { percent of the population could contract the } \\
\text { virus and so many people would need we want to } \\
\text { avoid those worst-case scenarios" }\end{array}$ \\
\hline Susceptibility & $\begin{array}{l}\text { Videos referencing key CDC susceptibility statements: } \\
\text { - Risk for severe illness increases with age } \\
\text { - Older adults at increased risk with those aged } 85 \text { or older are at the } \\
\text { greatest risk } \\
\text { - Those of any age with certain underlying medical conditions are at } \\
\text { increased risk } \\
\text { - Other potential risk factors (pregnancy, sociodemographic factors, } \\
\text { and environmental factors, etc.) }\end{array}$ & $\begin{array}{l}\text { "...over } 65 \text { years old and citizens suffering from } \\
\text { chronic diseases such as diabetes mellitus bronchial } \\
\text { asthma cancer diseases as well as those who have } \\
\text { suffered a heart attack or stroke are obliged to } \\
\text { observe the home regime" }\end{array}$ \\
\hline Self efficacy & $\begin{array}{l}\text { Videos referencing } \\
\text { - Individual behaviors recommended by the CDC (e.g., covering } \\
\text { - cough, vaccine) } \\
\text { - } \text { "Hoordinated/societal-level behaviors (e.g., closings, quarantines) } \\
\text { - Words of encouragement } \\
\text { - Instructions/links to other health resources }\end{array}$ & $\begin{array}{l}\text { "Avoid long walks and crowded places. Keep a social } \\
\text { distance of } 2 \text { meters. Take care of yourself and your } \\
\text { loved ones" }\end{array}$ \\
\hline $\begin{array}{l}\text { Response } \\
\text { efficacy }\end{array}$ & $\begin{array}{l}\text { Videos referencing } \\
\text { - Discussion whether recommended actions were effective or not } \\
\text { - Mentioned the number of those who recovered from the virus } \\
\text { - Individuals who had triumphed over the virus and their stories. }\end{array}$ & $\begin{array}{l}\text { "the contact tracing and quarantine and the public } \\
\text { health measures are very effective at bringing the } \\
\text { outbreak under control that can dramatically reduce } \\
\text { the number of cases" }\end{array}$ \\
\hline
\end{tabular}


Table 2

General descriptions of COVID- related videos for seven countries.

\begin{tabular}{|c|c|c|c|c|}
\hline Countries & $\begin{array}{l}\text { No. of observations (unique) } \\
\text { [\% out of all trending video] }\end{array}$ & Major video categories & $\begin{array}{c}\text { First } \\
\text { appeared on }\end{array}$ & Title of the first video \\
\hline Taiwan & $\begin{array}{l}4,099(555) \\
{[4.5 \%]}\end{array}$ & $\begin{array}{l}\text { News \& Politics }(79.2 \%) \\
\text { People \& Blogs }(9.4 \%) \\
\text { Music }(4.5 \%)\end{array}$ & 01 Jan & $\begin{array}{l}\text { 武漢染 SARS...台商大本營恐淪陷？兩岸全面警戒！SARS 現蹤武漢！毛寶 } \\
\text { 漲停、康那香逾半根停板！-【這！不是新聞 精華篇】20191231-4 / 這!不是 } \\
\text { 新聞 } \\
\text { [ Wuhan suffers from SARS...Taiwan business base camp may fall? Fully alert } \\
\text { across the strait! SARS is now in Wuhan! Maobao daily limit, Kang Naxiang } \\
\text { more than half of the limit! /This! Not news, essence 20191231-4 ]/ This! Not } \\
\text { news }\end{array}$ \\
\hline $\begin{array}{l}\text { New } \\
\text { Zealand }\end{array}$ & $\begin{array}{l}6,770(432) \\
{[7.1 \%]}\end{array}$ & $\begin{array}{l}\text { News \& Politics }(67.4 \%) \\
\text { Comedy }(10.6 \%) \\
\text { Entertainment }(8.2 \%)\end{array}$ & 22 Jan & 24 Oras Express: January 21, 2020/ GMA News \\
\hline Russia & $\begin{array}{l}5,222(1344) \\
{[6.1 \%]}\end{array}$ & $\begin{array}{l}\text { News \& Politics }(47.1 \%) \\
\text { People \& Blogs }(14.9 \%) \\
\text { Entertainment }(7.6 \%)\end{array}$ & 22 Jan & $\begin{array}{l}\text { Минск переключается, Миллиарды пенсионеров, Китайский вирус // } \\
\text { Галопом по Европам \#140/ Константин Сёмин } \\
\text { [ Minsk switches, Billions of pensioners, Chinese virus // Gallop across Europe \# } \\
\text { 140/ Konstantin Semin ] }\end{array}$ \\
\hline Canada & $\begin{array}{l}5,874(364) \\
{[5.7 \%]}\end{array}$ & $\begin{array}{l}\text { News \& Politics }(65.4 \%) \\
\text { Education }(8.4 \%) \\
\text { Entertainment }(7.3 \%)\end{array}$ & $25 \mathrm{Jan}$ & China puts millions under lockdown to contain coronavirus / $\mathrm{DWNews}$ \\
\hline $\begin{array}{l}\text { United } \\
\text { States }\end{array}$ & $\begin{array}{l}5,476(322) \\
{[5.5 \%]}\end{array}$ & $\begin{array}{l}\text { News \& Politics }(63.5 \%) \\
\text { Education }(9.1 \%) \\
\text { Entertainment }(8.3 \%)\end{array}$ & 26 Jan & $\begin{array}{l}\text { Coronavirus spread is 'accelerating' says China as death toll rises to } 41 \text { / Channel } \\
4 \text { News }\end{array}$ \\
\hline Brazil & $\begin{array}{l}2,463(125) \\
{[2.4 \%]}\end{array}$ & $\begin{array}{l}\text { Entertainment }(22.0 \%) \\
\text { News \& Politics }(20.9 \%) \\
\text { Music }(16.2 \%)\end{array}$ & 28 Jan & $\begin{array}{l}\text { O CORONAVÍRUS e a POLÊMICA de Cyberpunk 2077/ Gameplayrj } \\
\text { [ THE CORONAVIRUS AND THE POLITICS OF Cyberpunk 2077// } \\
\text { Gameplayrj ] }\end{array}$ \\
\hline
\end{tabular}


Table 3

Games-Howell Multiple Comparisons for different countries on threat and efficacy portrayals.

\begin{tabular}{|c|c|c|c|c|c|c|c|c|c|c|c|}
\hline \multirow[b]{2}{*}{$\begin{array}{c}(I) \\
\text { Country }\end{array}$} & \multirow[b]{2}{*}{$\begin{array}{c}(J) \\
\text { Country }\end{array}$} & \multicolumn{2}{|c|}{ Severity } & \multicolumn{2}{|c|}{ Susceptibility } & \multicolumn{2}{|c|}{ Self efficacy } & \multicolumn{2}{|c|}{ Response efficacy } & \multicolumn{2}{|c|}{ Threat-Efficacy } \\
\hline & & $\begin{array}{l}\mathrm{MD} \\
(I-J)\end{array}$ & $S E$ & $\begin{array}{l}\mathrm{MD} \\
(I-J)\end{array}$ & $S E$ & $\begin{array}{l}\mathrm{MD} \\
(I-J)\end{array}$ & $S E$ & $\begin{array}{l}\mathrm{MD} \\
(I-J)\end{array}$ & $S E$ & $\begin{array}{l}\mathrm{MD} \\
(I-J)\end{array}$ & $S E$ \\
\hline \multirow[t]{5}{*}{ Russia } & United States & $.008 * * *$ & .001 & $.002 * * *$ & .000 & -.001 & .001 & $-.002 * * *$ & .000 & $.012 * * *$ & .001 \\
\hline & Brazil & .003 & .003 & .000 & .001 & .002 & .001 & .000 & .000 & .002 & .002 \\
\hline & Canada & $.011 * * *$ & .002 & .001 & .001 & -.003 & .001 & $-.001 * * *$ & .000 & $.016^{* * *}$ & .001 \\
\hline & Taiwan & $.011 * *$ & .003 & $.003 *$ & .001 & .000 & .002 & -.000 & .000 & $.015^{* * *}$ & .002 \\
\hline & New Zealand & $.014 * * *$ & .001 & $.003 * * *$ & .000 & $.004 * * *$ & .001 & .001 & .000 & $.014 * * *$ & .001 \\
\hline \multirow[t]{4}{*}{ United States } & Brazil & -.005 & .003 & -.002 & .001 & .002 & .002 & $.002 * * *$ & .000 & $-.011 *$ & .002 \\
\hline & Canada & .003 & .002 & -.001 & .001 & -.002 & .001 & .000 & .000 & .004 & .002 \\
\hline & Taiwan & .003 & .003 & .001 & .001 & .001 & .002 & .001 & .000 & .002 & .002 \\
\hline & New Zealand & $.006^{*}$ & .002 & .001 & .001 & $.004 * * *$ & .001 & $.001 *$ & .000 & .001 & .001 \\
\hline \multirow[t]{3}{*}{ Brazil } & Canada & .008 & .003 & .001 & .001 & -.004 & .002 & $-.001 * *$ & .000 & $.015^{* * *}$ & .002 \\
\hline & Taiwan & .008 & .004 & .003 & .001 & .002 & .002 & -.000 & .001 & $.013^{*}$ & .003 \\
\hline & New Zealand & $.011 * *$ & .003 & $.003 *$ & .001 & .002 & .002 & -.001 & .000 & $.012 * *$ & .002 \\
\hline \multirow[t]{2}{*}{ Canada } & Taiwan & .000 & .003 & .002 & .001 & .002 & .002 & .001 & .001 & -.001 & .003 \\
\hline & New Zealand & .002 & .002 & $.002 *$ & .001 & $.006 * * *$ & .001 & .001 & .000 & -.003 & .001 \\
\hline Taiwan & New Zealand & .002 & .003 & .000 & .001 & .004 & .002 & -.000 & .000 & -.001 & .002 \\
\hline
\end{tabular}

Note. $\mathrm{MD}=$ Difference in Mean, $\mathrm{SE}=$ Standard Error.

$* p<.05 . * * p<.01 . * * * p<.001$. 
Figure 1

Construct density scores across six countries.
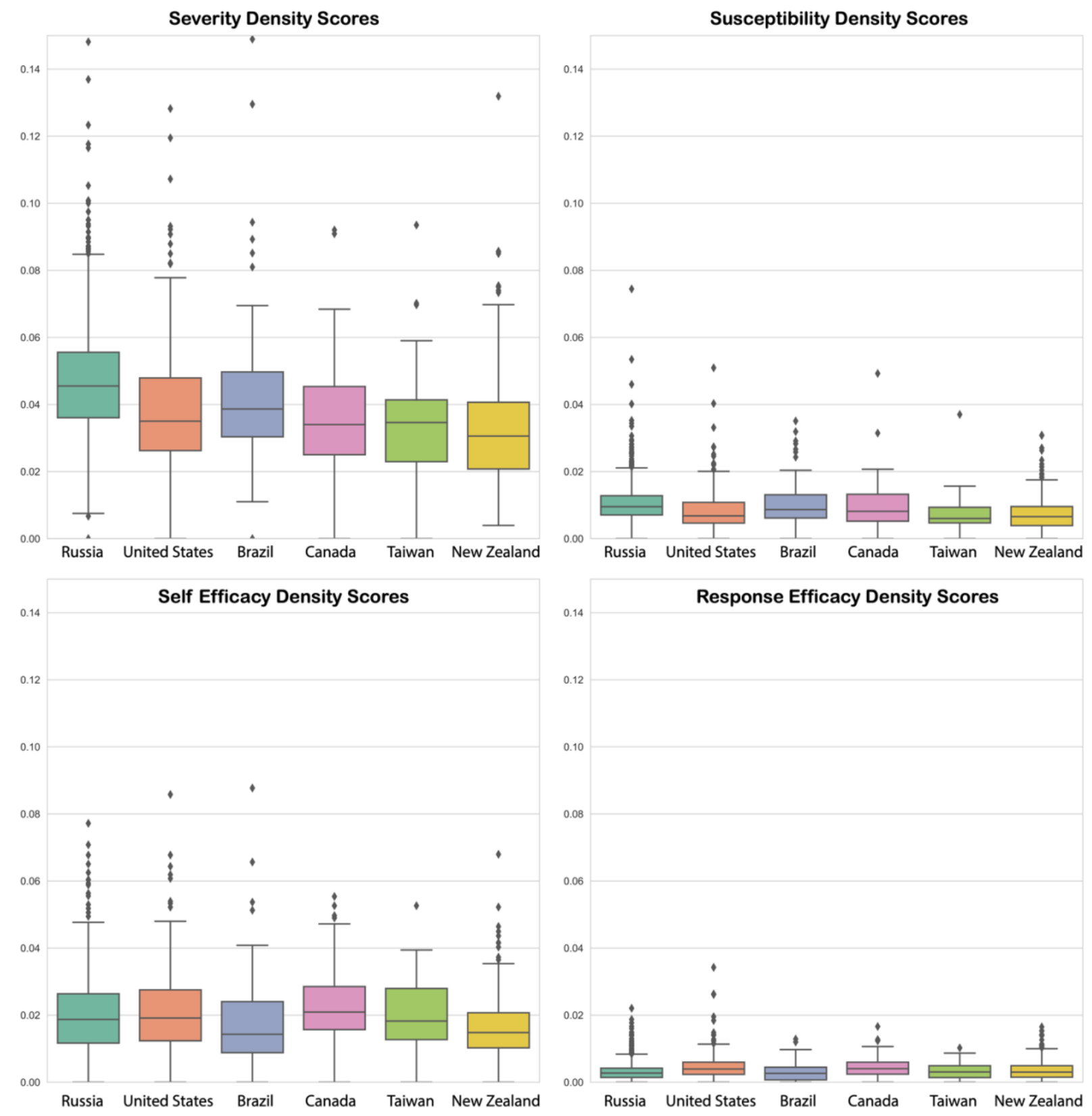